07

\title{
Омические контакты к оксиду европия для устройств спинтроники
}

\author{
(ㄷ А.А. Андреев, Ю.В. Грищенко, И.А. Черных, М.Л. Занавескин, Э.Ф. Лобанович \\ Национальный исследовательский центр „Курчатовский институт“, Москва, Россия \\ E-mail: andreev_aa@nrcki.ru
}

Поступило в Редакцию 19 декабря 2018 г.

В окончательной редакции 15 января 2019 г.

Принято к публикации 15 января 2019 г.

\begin{abstract}
Предложена методика in situ создания омических контактов к $\mathrm{EuO}$ на основе алюминия методом молекулярно-пучковой эпитаксии. Сформированные контакты характеризуются линейной вольт-амперной характеристикой, обладают контактным сопротивлением $0.55 \Omega \cdot \mathrm{mm}$ и стабильны на воздухе, что свидетельствует о перспективности использования предложенной технологии для формирования устройств спинтроники.
\end{abstract}

DOI: 10.21883/PJTF.2019.07.47536.17649

Ферромагнитный полупроводник оксид европия (EuO) перспективен для создания устройств спиновой электроники на кремнии, так как является магнитополяронным материалом, в котором переход проводник-изолятор может быть обусловлен только магнитной составляющей $[1,2]$. Проводимость $\mathrm{EuO}$ можно регулировать в широких пределах путем легирования редкоземельными элементами ( $\mathrm{Gd}, \mathrm{La}$ или $\mathrm{Lu})$ или кислородными вакансиями без уменьшения степени спиновой поляризации электронов, что делает $\mathrm{EuO}$ уникальным материалом при использовании в качестве инжектора спина [3]. Успехи в создании новых устройств спинтроники, базовым материалом которых является $\mathrm{EuO}$, зависят не только от качества исходного полупроводникового материала, но и от свойств сформированных омических контактов к нему.

Однако создание контактов к $\mathrm{EuO}$ является нетривиальной задачей, и данный вопрос практически не освещен в открытых источниках. Основной проблемой является деградация пленок $\mathrm{EuO}$ на воздухе с образованием немагнитных высших оксидных фаз $\mathrm{Eu}_{2} \mathrm{O}_{3}$ и $\mathrm{Eu}_{3} \mathrm{O}_{4}$ [2,4]. В работе [5] предложен способ формирования контактов с использованием in situ осажденных защитных слоев $\mathrm{Ti}, \mathrm{Si}$ или $\mathrm{Al}_{2} \mathrm{O}_{3}$ для предотвращения деградации пленок $\mathrm{Eu}_{1-y} \mathrm{La}_{y} \mathrm{O}_{1-x}$. Авторами рассматривается возможность формирования омических контактов на основе лантана, покрытого золотом $(\mathrm{Au} / \mathrm{La})$, и из ниобия. Отмечается, что контакт $\mathrm{Au} / \mathrm{La}$ деградирует со временем. В результате авторы указанной работы признали удовлетворительными контакты из ниобия, обеспечивающие омический контакт. Однако существенным недостатком предлагаемого подхода является необходимость вытравливания защитного слоя для последующего нанесения контактного слоя, что может приводить к повреждению поверхности пленки $\mathrm{Eu}_{1-y} \mathrm{La}_{y} \mathrm{O}_{1-x}$. Таким образом, большой интерес представляет разработка метода формирования контактов к пленкам EuO. В частности, важным аспектом являются материал контактов и технология их изготовления для обеспечения низкого контактного сопротивления и достижения его долговременной стабильности с сохранением электрофизических свойств ЕuO.

В настоящей работе исследовалась возможность создания контактов на основе алюминия к пленкам $\mathrm{Eu}_{1-y} \mathrm{Gd}_{y} \mathrm{O}$, выращенным на пластинах оксида циркония, стабилизированного оксидом иттрия (YSZ (100)). Материал подложки выбран благодаря его диэлектрическим свойствам при комнатной температуре, что предотвращает шунтирование сопротивления активного слоя подложкой. Алюминий обладает хорошими барьерными свойствами по отношению к кислороду, что позволяет использовать его не только в качестве контактного, но и в качестве защитного слоя для $\mathrm{Eu}_{1-y} \mathrm{Gd}_{y} \mathrm{O}$.

Пленки $\mathrm{Eu}_{1-y} \mathrm{Gd}_{y} \mathrm{O}$ толщиной $100 \mathrm{~nm}$ были выращены на подложках YSZ в установке молекулярно-пучковой эпитаксии Riber Compact 12. После завершения ростового процесса in situ был сформирован слой алюминия толщиной $100 \mathrm{~nm}$. Важными моментами были откачка камеры от следов кислорода после роста, охлаждение образца (температура по термопаре в нагревателе подложки составляла не более $\left.313 \mathrm{~K}\left(40^{\circ} \mathrm{C}\right)\right)$ и обеспечение вакуума лучше чем $10^{-7} \mathrm{~Pa}$; в противном случае $\mathrm{Al}$ осаждался с образованием $\mathrm{Al}_{2} \mathrm{O}_{3}$.

Технологически контакты формировались следующим образом. На образцы наносился с помощью плазмохимического осаждения слой $\mathrm{SiO}_{2}$ толщиной $100 \mathrm{~nm}$. По слою резиста в $\mathrm{SiO}_{2}$ вскрывались окна для травления Al. Контакты формировались путем реактивного плазменного травления слоя $\mathrm{Al}$ по маске $\mathrm{SiO}_{2}$ в хлорсодержащей плазме. Немедленно после травления в условиях вакуума (лучше чем $10^{-3} \mathrm{~Pa}$ ) образец переносился в камеру осаждения, где покрывался слоем аморфного $\mathrm{Si}_{3} \mathrm{~N}_{4}$ толщиной $100 \mathrm{~nm}$. После охлаждения образца проводилась литография и вскрытие окон в диэлектриках $\mathrm{Si}_{3} \mathrm{~N}_{4}(100 \mathrm{~nm}) / \mathrm{SiO}_{2}(100 \mathrm{~nm})$ в хлорсодержащей плазме. Усиление контактов не производилось. Структура образца и последовательность операций в процессе изготовления контактов приведены на рис. 1. 
$a$

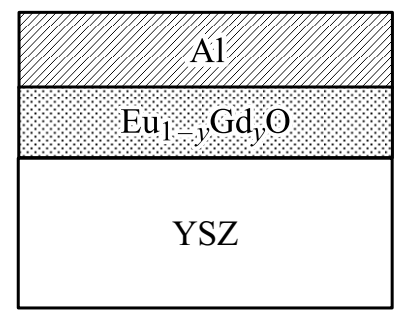

$c$

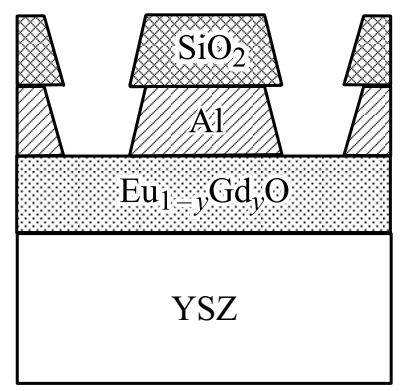

Рис. 1. Последовательность изготовления контактов. $a$ - начальная структура, $b-$ осаждение $\mathrm{SiO}_{2}$ и вскрытие окон по маске PMМА, $c$ - травление слоя $\mathrm{Al}$ по маске $\mathrm{SiO}_{2}$, $d$ - осаждение защитного слоя $\mathrm{Si}_{3} \mathrm{~N}_{4}$.

Для измерения переходного сопротивления контактов использовались планарные электроды и четырехзондовый метод измерения сопротивления методом ,длинной линии“ с радиальной геометрией контактных площадок, это позволяет обойтись без изоляции отдельных тестовых структур и уменьшает эффекты, связанные с протеканием тока на наружных краях контактных площадок [6]. Использовался набор контактов с постоянным внутренним радиусом $a=80 \mu \mathrm{m}$ и меняющимся внешним радиусом $(a+s)$, где $s-$ ширина зазора между контактами $s=2-40 \mu \mathrm{m}$.

Все полученные структуры имели линейную вольтамперную характеристику (BAX) с наклоном, зависящим от ширины зазора, и с увеличением расстояния между контактами их сопротивление увеличивалось. На рис. 2 представлена типичная ВАХ контакта $\mathrm{Al} / \mathrm{Eu}_{1-y} \mathrm{Gd}_{y} \mathrm{O}$ с шириной зазора $4 \mu \mathrm{m}$ между контактами при $T=300 \mathrm{~K}$. Контакты демонстрируют хорошую линейность и отсутствие выпрямляющих свойств.

Для определения сопротивления омического контакта $R_{c}$ был использован метод, предложенный в работе [7]. Для этого была построена зависимость полного нормированного сопротивления $R_{t o t c o r}=R_{t o t} / C$ от расстояния между контактами $s$ (рис. 3). Нормирующий коэффициент, учитывающий неравномерность удельного значения тока на единицу длины контакта для внутреннего и внешнего контакта, вычислялся по формуле

$$
C=\frac{a}{s} \ln \left(1+\frac{a}{s}\right) .
$$

Общее нормированное сопротивление задается формулой

$$
R_{\text {tot cor }}=\frac{R_{s}}{2 \pi a}\left[s+2 L_{t}\right],
$$

где $R_{s}$ - слоевое сопротивление пленки $\mathrm{Eu}_{1-y} \mathrm{Gd}_{y} \mathrm{O}$, $L_{t}$ - длина переноса (расстояние, на котором ток под контактом уменьшается в $e$ раз).

Отсечка прямой $R_{\text {tot cor }}(s)$ по оси ординат соответствует удвоенному приведенному сопротивлению контакта $R_{c}$, отсечка по оси абсцисс - удвоенной длине переноса $L_{t}$, а наклон прямой при известном радиусе внутреннего контакта определяет слоевое сопротивление $R_{s}$.

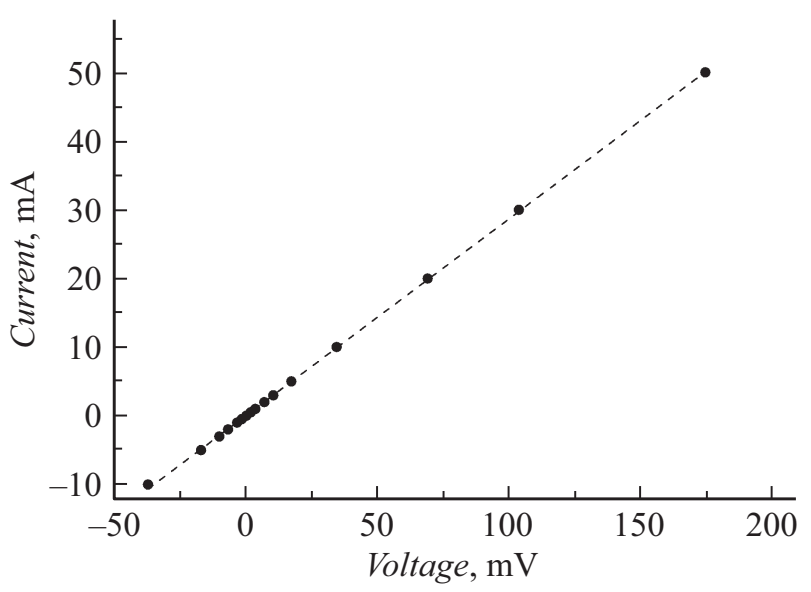

Рис. 2. ВАХ для сформированных контактов с радиусом внутреннего круга $80 \mu \mathrm{m}$ и шириной зазора между контактами $4 \mu \mathrm{m}$.

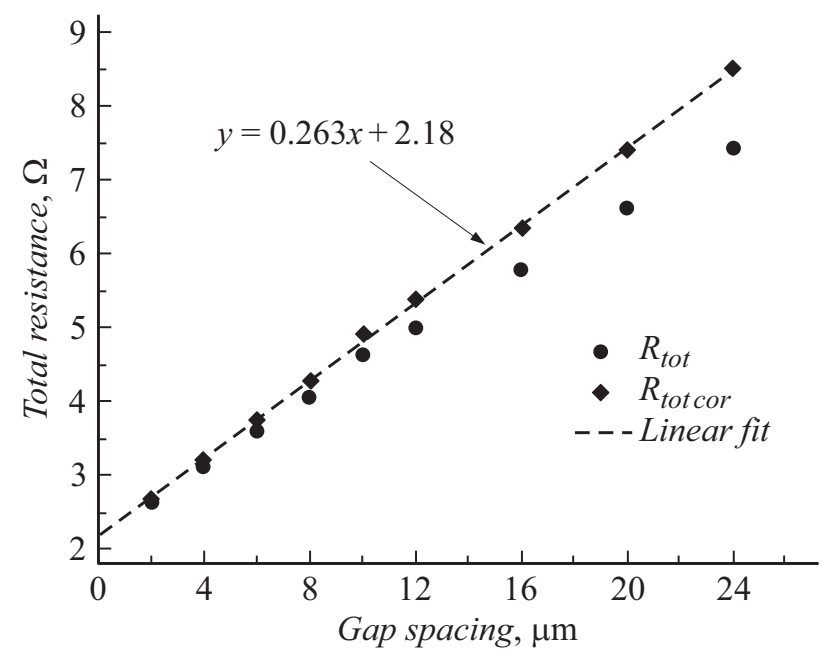

Рис. 3. Зависимость общего сопротивления от ширины зазора между контактами без учета (кружки) и с учетом (ромбы) коррекции геометрических факторов для кольцевых контактов. 
Удельное приведенное контактное сопротивление определяется следующим образом:

$$
\rho_{c}=R_{c} 2 \pi a[\Omega \cdot \mathrm{mm}] .
$$

С помощью линейной аппроксимации зависимости $R_{\text {tot cor }}(s)$ (рис. 3) определены следующие значения сопротивлений: $R_{s}=130 \Omega / \square, \rho_{c}=0.55 \Omega \cdot \mathrm{mm}$. Слоевое сопротивление пленки близко к значению сопротивления для образца-свидетеля, составившему $100 \Omega / \square$ по данными холловских измерений. Отметим, что при повторных измерениях через 14 дней были получены те же результаты, что указывает на отсутствие деградации сформированного контакта $\mathrm{Al} / \mathrm{Eu}_{1-y} \mathrm{Gd}_{y} \mathrm{O}$.

Предложена уникальная методика in situ формирования контактов на основе алюминия, позволяющая создать омический контакт к $\mathrm{EuO}$, не допустив взаимодействия пленки с атмосферой. Сформированные контакты $\mathrm{Al} / \mathrm{Eu}_{1-y} \mathrm{Gd}_{y} \mathrm{O}$ показывают линейную $\mathrm{BAX}$ и обладают контактным сопротивлением $0.55 \Omega \cdot \mathrm{mm}$. Омические контакты не деградируют со временем, что свидетельствует о перспективности использования предложенной технологии для формирования устройств спинтроники.

Работа выполнена при поддержке НИЦ „Курчатовский институт“ (приказ от 23.08.2017 г. № 1381).

\section{Список литературы}

[1] Sutarto R., Altendorf S.G., Coloru B., Moretti Sala M., Haupricht T., Chang C.F., Hu Z., Schüßler-Langeheine C., Hollmann N., Kierspel H., Hsieh H.H., Lin H.-J., Chen C.T., Tjeng L.H. // Phys. Rev. B. 2009. V. 79. P. 205318 (1-9).

[2] Mairoser T., Mundy J.A., Melville A., Hodash D., Cueva P., Held R., Glavic A., Schubert J., Muller D.A., Schlom D.G., Schmehl A. // Nature Commun. 2015. V. 6. P. 7716 (1-7).

[3] Averyanov D.V., Sadofyev Y.G., Tokmachev A.M., Primenko A.E., Likhachev I.A., Storchak V.G. // ACS Appl. Mater. Interfaces. 2015. V. 7. P. 6146-6152.

[4] Gerber T., Lömker P., Zijlstra B., Besson C., Mueller D.N., Zander W., Schubert J., Gorgoi M., Müller M. // J. Mater. Chem. C. 2016. V. 4. P. 1813-1820.

[5] Schmehl A., Vaithyanathan V., Herrnberger A., Thiel S., Richter C., Liberati M., Heeg T., Rockerath M., Kourkoutis L.F., Muhlbauer S., Boni P., Muller D.A., Barash Y., Schubert J., Idzerda Y., Mannhart J., Schlom D.G. // Nature Mater. 2007. V. 6. P. 882-887.

[6] Андреев А.Н., Растегаева М.Г., Растегаев В.П., Решанов С.A. // ФТП. 1998. Т. 32. В. 7. С. 832-838.

[7] Klootwijk J.H., Timmering C.E. // Proc. IEEE 2004 Int. Conf. on microelectronic test structures. IEEE, 2004. V. 17. P. $247-$ 252 . 